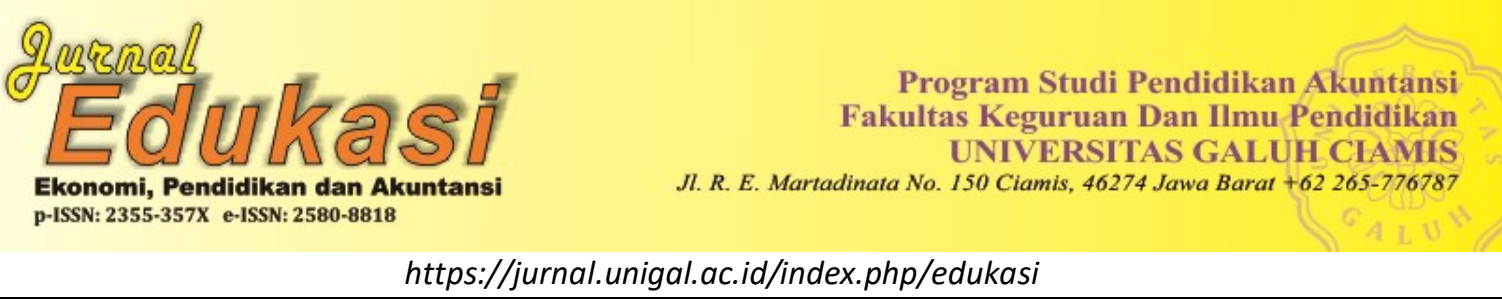

\title{
PERBANDINGAN PENILAIAN EKSPEKTASI, KUALITAS LAYANAN, DAN TINGKAT KEPUASAN PELANGGAN PADA HOTEL PUDU MALAYSIA
}

\author{
Oleh: \\ Kartika Damayanti ${ }^{1}$, Asep Kurniawan ${ }^{2}$ \\ Program Studi Akuntansi Sekolah Tinggi Ilmu Ekonomi Sutaatmadja, Indonesia \\ Email : kartikadamayanti2622@gmail.com \\ Sejarah Artikel: Diterima Maret 2020, Disetujui April 2020, Dipublikasikan Juni 2020
}

\begin{abstract}
ABSTRAK
Studi ini membandingkan penilaian mahasiswa program studi akuntansi dan manajemen untuk ekspektasi layanan dan kualitas layanan serta kepuasan pelanggan setelah menggunakan layanan penginapan yang disediakan oleh Hotel Sentral Pudu Malaysia. Teknik pengambilan sampel menggunakan simple random sampling. Berdasarkan kriteria ini, sampel yang didapatkan adalah 114 mahasiswa. Alat analisis dalam penelitian ini adalah uji perbedaan non-parametrik yang terdiri dari uji Kolmogorov-smirnov dan uji mann-whitney. Hasil penelitian menunjukkan bahwa menurut uji tersebut tidak ada perbedaan yang signifikan dalam penilaian ekspektasi layanan antara mahasiswa program studi akuntansi dan manajemen. Untuk kualitas layanan, tes Kolmogorov-Smirnov menunjukkan bahwa tidak ada perbedaan yang signifikan dalam penilaian tingkat kualitas layanan antara mahasiswa program studi akuntansi dan manajemen, sedangkan tes Mann-Whitney secara signifikan terdapat perbedaan penilaian tingkat kualitas layanan antara mahasiswa program studi akuntansi dan manajemen. Dan untuk kepuasan pelanggan, dalam dua tes dinyatakan terdapat perbedaan signifikan terhadap tingkat kepuasan pelanggan antara mahasiswa program studi akuntansi dan manajemen.
\end{abstract}

Kata Kunci: Ekspektasi, Kepuasan Pelanggan, Kualitas Layanan, Mahasiswa, Perbandingan.

\section{ABSTRACT}

This study compares the value of accounting and management study programs students for service expectations and service quality and customer satisfaction after using lodging services provided by the Sentral Pudu Malaysia Hotel. The sampling technique uses simple random sampling. Based on these criteria, the sample obtained was 114 students. The analytical tool in this study is non-parametric consisting of the Kolmogorov-smirnov test and the mann-whitney test. The results showed that according to the test there were no significant differences in the assessment of service expectations between accounting and management study program students. For service quality, the KolmogorovSmirnov test shows that there is no significant difference in the assessment of service quality levels between accounting and management study program students, while the Mann-Whitney test has significant differences in the assessment of service quality levels between accounting and management study program students. And for customer satisfaction, in the two tests stated there are significant differences in the level of customer satisfaction between students of accounting and management study programs.

Keywords: Expectations, Customer Satisfaction, Service Quality, Students, Comparison

\section{PENDAHULUAN}

Dewasa ini, perusahaan-perusahaan banyak yang bersaing untuk memperluas pasarnya. Perluasan pasar ini nantinya akan membuat penjualan meningkat dan akhirnya perusahaan dapat memiliki lebih banyak lagi konsumen. Namun, perusahaan sebagai produsen harus memahami bahwa semakin banyak konsumen, 
maka perusahaan akan kesulitan untuk mengenali konsumennya. Yang paling utama adalah tentang suka atau tidaknya konsumen terhadap barang atau jasa yang ditawarkan serta alasan yang mendasarinya.

Perusahaan telah menghabiskan banyak dana untuk membuat pelanggan loyal terhadap produk serta layanan mereka. Selama beberapa dekade, pemasar telah bekerja tanpa lelah agar mampu mendapatkan hadiah yang diimpikan tetapi tampaknya sulit dipahami, yaitu kepuasan pelanggan yang diyakini mengarah pada loyalitas pelanggan dan mendorong bisnis yang berulang atau. Layanan yang memiliki kualitas tinggi akan membuat konsumen menjadi puas dan akan terus membeli atau menggunakan produk yang sama, dan sebaliknya layanan yang berkualitas rendah akan membuat konsumen tidak akan menggunakan produk yang sama. Selama perusahaan bisa memberi-kan layanan yang berkualitas, maka perusahaan tersebut akan mengharapkan pelanggan yang puas dan bisnis yang berulang (Parasuraman, Zeithaml, and Berry, 1985, 1988).

Kesesuaian harapan dan kenyataan yang mampu dirasakan pelanggan atas kinerja yang dihasilkan merupakan arti dari kepuasan pelanggan. Salah satu ciri pelanggan yang merasa puas atas produk atau layanan sebuah perusahaan yaitu dengan menggunakannya secara kontinyu, sehingga akan memiliki dampak positif terhadap eksistensi atau keberadaan perusahaan yang dilihat dari peningkatan penjualan dan laba yang memungkinkan perusahaan dapat berkembang. Kepuasan pelanggan sangat dibutuhkan guna mempertahankan dan mengembangkan usaha sehingga dapat meningkatkan persiangan (Prihatin, dkk, 2018).

Kepuasan pelanggan memang sangat penting untuk mengembangkan usaha atau memiliki dampak yang kuat pada kinerja bisnis. Tetapi perlu diingat bahwa pelanggan yang puas mungkin tidak selalu kembali dan pelanggan yang tidak puas tidak perlu berganti. Seperti survey yang dilakukan oleh Taylor (1998) yang menunjukkan bahwa hingga $70 \%$ pelanggan yang puas akan mempertimbangkan untuk beralih ketika opsi lain disediakan.

Menurut Kotler (2006) dalam Istiqo M dan Poernomo (2017), untuk meningkatkan persaingan masing-masing perusahaan harus dapat memenangkan persaingan tersebut dengan menghasilkan produk/jasa yang terbaik dan dapat memenuhi selera konsumen yang selalu berkembang dan berubah-ubah. Salah satu perkembangan yang semakin ketat adalah perkembangan bisnis hotel. Terbukti dengan banyaknya hotel-hotel baru yang berdiri.

Pada umumnya harapan dipandang sebagai seperangkat kriteria yang dimiliki konsumen terhadap suatu layanan atau produk. Sedangkan kualitas layanan merupakan penilaian umum, keseluruhan dari suatu layanan atau produk yang dirancang dan dimaksudkan oleh yang menyediakan layanan dan dirasakan oleh pelanggan (Rungting, 2004). Dengan kata lain harapan disini merupakan harapan awal pelanggan sebelum menggunakan produk atau layanan, sedangkan kualitas layanan merupakan apa yang dirasakan oleh pelanggan setelah menggunakan produk atau layanan tersebut.

Penelitian ini tidak mengabaikan pentingnya harapan dalam evaluasi layanan pelanggan. Karena harapan pelanggan sangat penting untuk membentuk pengalaman mereka. Penilaian kepuasan memiliki kaitan yang erat dengan harapan awal (ekspektasi) mereka terhadap penyedia layanan.

Sekolah Tinggi Ilmu Ekonomi Sutaatmadja Subang memiliki sebuah agenda tahunan yaitu Kuliah Kerja Lapangan. Untuk tahun 2019 ini Sekolah Tinggi Ilmu Ekonomi Sutaatmadja Subang mengajak mahasiswanya yang terdiri dari program studi Akuntansi dan Manajemen untuk mengadakan program KKL di Malaysia selama 3 hari 2 malam. Tujuan dari program KKL ini adalah menambah wawasan serta pengetahuan mahasiswa. Dalam program KKL ini, seluruh mahasiswa menggunakan jasa penginapan yang disediakan oleh Hotel Sentral Pudu Malaysia. Dengan demikian tujuan dari penelitian ini adalah untuk membandingkan penilaian mahasiswa program studi akuntansi dan manajemen atas ekspektasi layanan dan kualitas layanan serta kepuasan pelanggan setelah menggunakan jasa penginapan yang disediakan oleh Hotel Sentral Pudu Malaysia. Diharapkan hasil penelitian ini dapat dijadikan sebagai referensi bagi penyedia layanan khususnya perusahaan perhotelan atau bisnis hotel dalam meningkatkan pelayanannya agar mampu bersaing dalam merebut hati pelanggan. Oleh karena itu peneliti tertarik untuk melakukan penelitian dengan judul

"Perbandingan Penilaian Ekspektasi, Kualitas Layanan, dan Tingkat Kepuasan Pelanggan pada Hotel Pudu Malaysia." METODE PENELITIAN 
Penelitian ini dilakukan di Sekolah Tinggi Ilmu Ekonomi Sutaatmadja Subang yang berlokasi di Jalan Otto Iskandardinata No. 76, Karanganyar, Subang, Jawa Barat, Indonesia. Waktu penelitian dilaksanakan pada tanggal 23 Agustus 2019 - 18 September 2019. Responden penelitian ini adalah mahasiswa Sekolah Tinggi Ilmu Ekonomi Sutaatmadja Subang semester 7 (tujuh) tahun ajaran 2019/2020 atau dalam hal ini peserta Kuliah Kerja Lapangan yang bertindak sebagai pengguna jasa layanan penginapan Hotel Sentral Pudu Malaysia sebanyak 114 responden yang terdiri atas mahasiswa program studi akuntansi dan manajemen. Metode penelitian yang digunakan yaitu penelitian kuantitatif. Teknik pengumpulan data yang digunakan yaitu dengan kuesioner dan pengukuran menggunakan skala likert. Teknik pemilihan sampel yang digunakan adalah simple random sampling yaitu pengambilan sampel secara acak, tanpa memperhatikan strata yang ada dalam populasi (Hidayat, 2017). Menurut Sugiyono (2008:199) "kuisioner merupakan teknik pengumpulan data yang dilakukan dengan cara memberi seperangkat pertanyaan atau pernyataan tertulis kepada responden untuk dijawab". Sedangkan Skala Likert merupakan alat yang digunakan untuk mengukur sikap, pendapat, dan persepsi seseorang atau sekelompok orang tentang fenomena sosial (Sugiyono, 2014:93).

Dalam penelitian ini menggunakan metode kuantitatif. Menurut Sugiyono (2014) metode kuantitatif merupakan metode penelitian yang didalamnya berupa angka-angka dan analisis menggunakan statistik.

Dalam penelitian ini, peneliti menggunakan statistik deskriptif. Menurut Sugiyono (2011) statistik deksriptif adalah metode statistik yang digunakan untuk menganalisis data dengan cara mendeskripsikan atau menggambarkan data yang telah terkumpul sebagaimana adanya tanpa bermaksud membuat kesimpulan yang berlaku untuk umum atau generalisasi.

Sebelum data di analisis lebih lanjut, data primer yang dididapat dari hasil mengumpulkan data disimpan dalam sebuah file Microsoft Excel 2013. Selain digunakan untuk mengolah data, Microsoft Excel 2013 juga digunakan untuk mengelola data karakteristik responden, setelah data primer dimasukkan ke dalam file Microsoft Excel 2013, data tersebut lalu diana-lisis menggunakan Software SPSS Versi 22. Adapun uji yang dilakukan untuk menganalisis data penelitian ini yaitu Uji Beda Non Parametrik yang terdiri dari Uji Kolmogorov-Smirnov Z dan Uji Mann-Whitney.

\section{HASIL PENELITIAN DAN PEMBAHASAN Hasil Uji Beda Non-Parametrik}

\section{a. Ekspektasi}

Tabel 1

\begin{tabular}{lccccc} 
& \multicolumn{5}{c}{ Statistik Deskriptif } \\
& N & Mean & Std. Deviation & Min & Max \\
\hline Total Ekpektasi & 114 & 62,06 & 6,213 & 47 & 78 \\
Program Studi & 114 & 1,50 & 0,502 & 1 & 2
\end{tabular}

Sumber : data diolah oleh peneliti tahun 2019

Tabel 1 menampilkan statistik deskriptif (jumlah pengamatan, rata-rata, simpangan baku, nilai maksimum dan nilai minimum), diperoleh jumlah pegamatan sebanyak 114 data, dan penilaian terbanyak adalah senilai 78. Sedangkan penilaian yang paling sedikit senilai 47.

\section{Two-Sample Kolmogorov-Smirnov Test}

Tabel 2

Frekuensi

\begin{tabular}{ccc} 
& $\begin{array}{c}\text { Frekuensi } \\
\text { Program Studi }\end{array}$ & N \\
\hline Total Ekspektasi & Akuntansi & 57 \\
& Manajemen & 57 \\
& Total & 114
\end{tabular}

Sumber : data diolah oleh peneliti tahun 2019

Table frekuensi, memaparkan banyaknya jumlah mahasiswa yang berasal dari program studi Akuntansi dan Manajemen yang melakukan penilaian. Adapun jumlah mahasiswa yang berasal dari 
Program Studi Akuntansi adalah 57 orang dan yang berasal dari Program Studi Manajemen adalah 57 orang.

Tabel 3

Hasil Uji Statistik

\begin{tabular}{llr} 
& & Total Ekspektasi \\
\hline Most Extreme Differences & Absolute & 0,175 \\
& Positive & 0,035 \\
& Negative & $-0,175$ \\
Kolmogorov-Smirnov Z & & 0,937 \\
Asymp. Sig. (2-tailed) & & 0,344 \\
\hline
\end{tabular}

a. Grouping Variable: Program Studi

Sumber : data diolah oleh peneliti tahun 2019

Tabel Test Statistik, memaparkan hasil uji Kolmogrov-Smirnov $=0.937$ dan terlihat bahwa pada kolom asymp sig (2-tailed) untuk diuji 2 sisi adalah 0.344 . Disini didapat probabilitas diatas 0.05 $(0.344>0.05)$.

\section{Mann-Whitney Test}

\begin{tabular}{llrrr} 
& \multicolumn{4}{c}{ Tabel 4} \\
Peringkat & & \\
& Program Studi & N & Mean Rank & Sum of Ranks \\
\hline Total Ekspektasi & Akuntansi & 57 & 61,18 & 3487,00 \\
& Manajemen & 57 & 53,82 & 3068,00 \\
& Total & 114 & &
\end{tabular}

Sumber : data diolah oleh peneliti tahun 2019

Berdasarkan tabel Peringkat, menunjukkan bahwa Program Studi Akuntansi memberikan ratarata penilaian lebih tinggi dari pada Program Studi Manajemen.

Tabel 5

Hasil Uji Statistik

\begin{tabular}{lr} 
& Total Ekspektasi \\
\hline Mann-Whitney U & 1415,000 \\
Wilcoxon W & 3068,000 \\
Z & $-1,196$ \\
Asymp. Sig. (2-tailed) & 0,232 \\
\hline
\end{tabular}

a. Grouping Variable: Program Studi

Sumber : data diolah oleh peneliti tahun 2019

Berdasarkan Tabel Hasil Uji Statistik, terlihat bahwa pada kolom Asymp. Sig/Asymptotic significance dua sisi adalah 0.232 . Sehingga diperoleh probabilitasnya di atas 0,05 .

\section{b. Kualitas Layanan}

\begin{tabular}{lrrrrr} 
& \multicolumn{3}{c}{ Tabel 6 } & & \\
& Ntatistik Deskriptif & & & \\
& & Mean & Std. Deviation & Min & Max \\
\hline Total Kualitas Layanan & 114 & 60,04 & 5,970 & 39 & 72 \\
Program_Studi & 114 & 1,50 & 0,502 & 1 & 2
\end{tabular}

Sumber : data diolah oleh peneliti tahun 2019 
Tabel 6 menampilkan statistik deskriptif (jumlah pengamatan, rata-rata, simpangan baku, nilai maksimum dan nilai minimum), diperoleh jumlah pegamatan sebanyak 114 data, dan penilaian terbanyak adalah senilai 72 . Sedangkan penilaian yang paling sedikit senilai 39 .

\section{Two-Sample Kolmogorov-Smirnov Test}

Tabel 7

Frekuensi

\begin{tabular}{llr} 
& Program_Studi & \multicolumn{1}{c}{ N } \\
\hline Total Kualitas Layanan & Akuntansi & 57 \\
& Manajemen & 57 \\
& Total & 114
\end{tabular}

Sumber : data diolah oleh peneliti tahun 2019

Table 7 frekuensi, memaparkan banyaknya jumlah mahasiswa yang berasal dari program studi Akuntansi dan Manajemen yang melakukan penilaian. Adapun jumlah mahasiswa yang berasal dari Program Studi Akuntansi adalah 57 orang dan yang berasal dari Program Studi Manajemen adalah 57 orang.

Tabel 8

Hasil Uji Statistik

\begin{tabular}{llr} 
& & Total Kualitas Layanan \\
\hline Most Extreme Differences & Absolute & 0,211 \\
& Positive & 0,018 \\
& Negative & $-0,211$ \\
Kolmogorov-Smirnov Z & & 1,124 \\
Asymp. Sig. (2-tailed) & & 0,160 \\
\hline
\end{tabular}

a. Grouping Variable: Program Studi

Sumber : data diolah oleh peneliti tahun 2019

Tabel 8 Test Statistik, memaparkan hasil uji Kolmogrov-Smirnov $=1,124$ dan terlihat bahwa pada kolom asymp sig (2-tailed) untuk diuji 2 sisi adalah 0,160 . Disini didapat probabilitas diatas $0,05(0,160$ $>0.05)$.

Mann-Whitney Test

Tabel 9

Peringkat

\begin{tabular}{llrrr} 
& Program Studi & \multicolumn{1}{c}{ N } & Mean Rank & Sum of Ranks \\
\hline Total Kualitas Layanan & Akuntansi & 57 & 64,09 & 3653,00 \\
& Manajemen & 57 & 50,91 & 2902,00 \\
& Total & 114 & &
\end{tabular}

Sumber : data diolah oleh peneliti tahun 2019

Berdasarkan tabel 9 Peringkat, menunjukkan bahwa Program Studi Akuntansi memberikan ratarata penilaian lebih tinggi dari pada Program Studi Manajemen. 
Tabel 10

Hasil Uji Statistik

Total Kualitas Layanan

\begin{tabular}{lr}
\hline Mann-Whitney U & 1249,000 \\
Wilcoxon W & 2902,000 \\
Z & $-2,145$ \\
Asymp. Sig. (2-tailed) & 0,032 \\
\hline
\end{tabular}

a. Grouping Variable: Program Studi

Sumber : data diolah oleh peneliti tahun 2019

Berdasarkan Tabel 10 Hasil Uji Statistik, terlihat bahwa pada kolom Asymp. Sig/Asymptotic significance dua sisi adalah 0,032 . Sehingga diperoleh probabilitasnya di bawah 0,05 .

\section{c. Kepuasan Pelanggan}

Tabel 11

Statistik Deskriptif

\begin{tabular}{lrrrrr} 
& N & Mean & Std. Deviation & Min & Max \\
\hline Total Kepuasan Pelanggan & 114 & 6,96 & 1,240 & 3 & 10 \\
Prodi & 114 & 1,50 & 0,502 & 1 & 2
\end{tabular}

Sumber : data diolah oleh peneliti tahun 2019

Tabel 11 menampilkan statistik deskriptif (jumlah pengamatan, rata-rata, simpangan baku, nilai maksimum dan nilai minimum), diperoleh jumlah pegamatan sebanyak 114 data, dan penilaian terbanyak adalah senilai 10. Sedangkan penilaian yang paling sedikit senilai 3 .

\section{Two-Sample Kolmogorov-Smirnov Test}

Tabel 12

Frekuensi

\begin{tabular}{llr} 
& Program Studi & N \\
\hline Total Kepuasan Pelanggan & Akuntansi & 57 \\
& Manajemen & 57 \\
& Total & 114
\end{tabular}

Sumber : data diolah oleh peneliti tahun 2019

Table 12 frekuensi, memaparkan banyaknya jumlah mahasiswa yang berasal dari program studi Akuntansi dan Manajemen yang melakukan penilaian. Adapun jumlah mahasiswa yang berasal dari Program Studi Akuntansi adalah 57 orang dan yang berasal dari Program Studi Manajemen adalah 57 orang.

Tabel 13

Hasil Uji Statistik

\begin{tabular}{llr} 
& & $\begin{array}{c}\text { Total Kepuasan } \\
\text { Pelanggan }\end{array}$ \\
\hline Most Extreme Differences & Absolute & 0,298 \\
& Positive & 0,018 \\
& Negative & $-0,298$ \\
Kolmogorov-Smirnov Z & & 1,592 \\
Asymp. Sig. (2-tailed) & & 0,013 \\
\hline
\end{tabular}

a. Grouping Variable: Program Studi

Sumber : data diolah oleh peneliti tahun 2019 
Tabel 13 Test Statistik, memaparkan hasil uji Kolmogrov-Smirnov = 1,592 dan terlihat bahwa pada kolom asymp sig (2-tailed) untuk diuji 2 sisi adalah 0,013. Disini didapat probabilitas dibawah $0,05(0,013<0.05)$.

\section{Mann-Whitney Test}

Tabel 14

Peringkat

\begin{tabular}{llrrr} 
& Program_Studi & \multicolumn{1}{c}{ N } & Mean Rank & Sum of Ranks \\
\hline \multirow{2}{*}{ Total Kepuasan Pelanggan } & Akuntansi & 57 & 66,08 & 3766,50 \\
& Manajemen & 57 & 48,92 & 2788,50 \\
& Total & 114 & &
\end{tabular}

Sumber : data diolah oleh peneliti tahun 2019

Berdasarkan tabel 14 Peringkat, menunjukkan bahwa Program Studi Akuntansi memberikan ratarata penilaian lebih tinggi dari pada Program Studi Manajemen

Tabel 15

Hasil Uji Statistik

\begin{tabular}{lr} 
& Total Kepuasan Pelanggan \\
\hline Mann-Whitney U & 1135,500 \\
Wilcoxon W & 2788,500 \\
Z & $-2,993$ \\
Asymp. Sig. (2-tailed) & 0,003 \\
\hline a. Grouping Variable: Program Studi & \\
Sumber : data diolah oleh peneliti tahun 2019
\end{tabular}

Berdasarkan Tabel 15 Hasil Uji Statistik, terlihat bahwa pada kolom Asymp. Sig/Asymptotic significance dua sisi adalah 0,003 . Sehingga diperoleh probabilitasnya di bawah 0,05 .

\section{Pembahasan \\ Ekspektasi}

Dari hasil uji beda non-parametik dalam uji Kolmogorov-smirnov z ditemukan hasil uji Kolmogorov-smirnov senilai 0.937 dan terlihat bahwa pada kolom Asymp. Sig (2-tailed) untuk diuji 2 sisi adalah 0.344 , didapatkan probabilitas diatas alpha $0.05(0.334>0.05)$ yang artinya $\mathrm{H} 1$ ditolak, berarti tidak terdapat perbedaan signifikan terhadap penilaian ekspektasi layanan antara mahasiswa prodi Akuntansi dan Manajemen. Sedangkan menurut hasil uji beda non-parametik dalam uji Mann-Whitney ditemukan hasil bahwa pada kolom Asymp. Sig. (2-tailed) dua sisi adalah 0.232 . sehingga probabilitasnya diatas $0.05(0.232<0.05)$. H1 ditolak berarti tidak terdapat perbedaan signifikan terhadap penilaian ekspektasi antara mahasiswa prodi Akuntansi dan Manajemen.
Dari hasil uji beda non-parametik dalam uji Kolmogorov-smirnov z ditemukan hasil uji Kolmogorov-smirnov senilai 1.124 dan terlihat bahwa pada kolom Asymp. Sig (2-tailed) untuk diuji 2 sisi adalah 0.160 , didapatkan probabilitas diatas alpha $0.05(0.160>0.05)$ yang artinya $\mathrm{H} 2$ ditolak, berarti tidak terdapat perbedaan signifikan terhadap penilaian kualitas layanan antara mahasiswa prodi Akuntansi dan Manajemen. Sedangkan menurut hasil uji beda non-parametik dalam uji Mann-Whitney ditemukan hasil bahwa pada kolom Asymp. Sig. (2-tailed) dua sisi adalah 0.032. sehingga probabilitasnya dibawah alpha $0.05(0.032<$ $0.05)$. H2 diterima berarti terdapat perbedaan signifikan terhadap penilaian kualitas layanan antara mahasiswa prodi Akuntansi dan Manajemen. 
Dari hasil uji beda non-parametik dalam uji Kolmogorov-smirnov z ditemukan hasil uji Kolmogorov-smirnov senilai 1.592 dan terlihat bahwa pada kolom Asymp. Sig (2-tailed) untuk diuji 2 sisi adalah 0.013 , didapatkan probabilitas dibawah alpha $0.05(0.013<0.05)$ yang artinya H3 diterima, berarti terdapat perbedaan signifikan terhadap penilaian tingkat kepuasan pelanggan antara mahasiswa prodi Akuntansi dan Manajemen. Sedangkan menurut hasil uji beda non-parametik dalam uji Mann-Whitney ditemukan hasil bahwa pada kolom Asymp. Sig. (2-tailed) dua sisi adalah 0.003 . sehingga probabilitasnya dibawah alpha $0.05(0.003<$ 0.05). H3 diterima berarti terdapat perbedaan signifikan terhadap penilaian tingkat kepuasan pelanggan antara mahasiswa prodi Akuntansi dan Manajemen.

\section{PENUTUP}

\section{Kesimpulan}

Berdasarkan hasil analisis data dan pembahasan yang telah dijelaskan sebelumnya, maka kesimpulan yang dapat diambil dalam penelitian ini adalah :

1. Untuk penilaian ekspektasi layanan mahasiswa program studi akuntansi dan manajemen pada Hotel Sentral Pudu Malaysia ditemukan kesimpulan bahwa dari dua uji beda non-parametrik yaitu Kolmogorov-smirnov $\mathrm{z}$ dan mann-whitney menjelaskan tidak terdapat perbedaan signfikan penilaian ekspektasi layanan mahasiswa program studi akuntansi dan manajemen pada Hotel Sentral Pudu Malaysia.

2. Untuk penilaian kualitas layanan mahasiswa program studi akuntansi dan manajemen pada Hotel Sentral Pudu Malaysia ditemukan kesimpulan bahwa dari kedua uji beda nonparametrik Kolmogorov-smirnov z ditemukan bahwa tidak terdapat perbedaan signfikan penilaian kualitas layanan mahasiswa program studi akuntansi dan manajemen pada Hotel Sentral Pudu Malaysia. Sedangkan berdasarkan uji mannwhitney ditemukan bahwa terdapat perbedaan signfikan penilaian kualitas layanan mahasiswa program studi akuntansi dan manajemen pada Hotel Sentral Pudu Malaysia.

3. Untuk penilaian tingkat kepuasan pelanggan mahasiswa program studi akuntansi dan manajemen pada Hotel Sentral Pudu Malaysia ditemukan kesimpulan bahwa dari dua uji beda non-parametrik yaitu Kolmogorov-smirnov z dan mann-whitney menjelaskan terdapat perbedaan signfikan penilaian tingkat kepuasan pelanggan mahasiswa program studi akuntansi dan manajemen pada Hotel Sentral Pudu Malaysia.

\section{Keterbatasan Penelitian}

Dalam penelitian ini ada banyak keterbatasan. Diantaranya kesulitan peneliti untuk mencari penelitian terdahulu yang membahas perbandingan penilaian. Selain itu peneliti juga kesulitan dalam mencari responden. Kurangnya responden menyebabkan peneliti memiliki data yang tidak normal sehingga menggunakan uji beda non-parametrik.

\section{Saran}

Saran berdasarkan hasil penelitian dan pembahasan diatas adalah, untuk penyedia layanan hotel, agar selalu memperhatikan setiap layanan yang diberikan kepada konsumen. Agar konsumen selalu merasa puas. Untuk penelitian selanjutnya diharapkan untuk menambah variabel lain yang berhubungan dengan penilaian. Selain itu diharapkan juga untuk menambah jumlah sampel penelitian.

\section{DAFTAR PUSTAKA}

Anonim. 2016. Pengertian Dimensi Kualitas Pelayanan Menurut Para Ahli. https://etalasepustaka.blogspot.com/2016 $/ 05 /$ pengertian-dimensi-kualitaspelayanan-menurut-para-ahli.html? $\mathrm{m}=1$. (19 September 2019)

Anonim. 2016. Kualitas Pelayana: Dimensi dan Cara Mengukurnya.

http://ciputrauceo.net/blog/2016/18/kualit as-pelayanan-dimensi-dan-caramengukurnya. (19 September 2019)

Anonim. 2018. 6 Teori Kepuasan Pelanggan Yang Perlu Kamu Kepoin. https://billionairecoach.co.id/entrepreneu rship/6-teori-kepuasan-pelanggan. (18 Septembe 2019).

Anonim. Arti Ekspektasi: Pengertian Menurut Para Ahli Serta Contohnya. 2019. https:/www.maxmanroe.com/vid/umum/ arti-ekspektasi.html. (19 September 2019).

Doane, D. P., and Seward, L. E. (2011). Applied Statistiks in Business \& Economics, McGraw-Hill/Irwin. 
Hengki, dkk. Peningkatan Kualitas Layanan Untuk Kepuasan Pelanggan Hotel. Jurnal Ekonomi dan Bisnis. Politeknik Bisnis Indonesia.

Hidayat, Anwar. 2017. Penjelasan Uji MannWhitney $U$ Test Lengkap. https://www.statistikian.com/2014/04/ma nn-whitney-u-test.html/amp. September 2019)

Istiqo, M. C., \& Poernomo, E. (2017). Pengaruh Kualitas Pelayanan, Harga, dan Faktor Emosional terhadap Kepuasan Pelanggan pada Hotel The Sun Sidoarjo. Jurnal Bisnis Indonesia, 8(1).

Karsono. (2007). Pengaruh Kualitas Pelayanan Pelanggan Terhadap Loyalitas Pelanggan Dengan Kepuasan dan Komplain Sebagi Variable Pemediasi.Fokus Manajerial, vol.5, no.2,pp. 10-31.

Kotler, P. d. (2012). Marketing Management. New Jersey: Prentice Hall.

Lakosono, Adityo. 2015. Pengertian Kepuasan Pelanggan dan Faktor-Faktor yang Mempengaruhinya Menurut Para Ahli.http://adityolaksono26.blogspot.com /2015/03/pengertian-kepuasan-

pelanggan-dan.html.(19 September 2019).

Ohyver, Margaretha. 2018. Uji Nonparametrik. https://socs.binus.ac.id/2018/12/08/ujinonparametrik/. (20 September 2019).

Prihatin, Y. T., Mursito, B., dan Wijayanti, A. (2018). Pengaruh Kualitas Produk, Kualitas Pelayanan dan Faktor Emosi terhadap Kepuasan Pelanggan di UD Toko Pelangi Surakarta. Indonesian Economics Business and Management Research, 1(1).

Roen, Ferry. 2012. Teori Harapan. http://perilakuorganisasi.com/teoriharapan.html. (18 Septembe 2019).

Sugiyono. 2011. Metode Penelitian Kuantitatif, Kualitatif dan R\&D. Bandung: Afabeta

Sugiyono. 2014. Metode Penelitian Kuantitatif, Kualitatif dan R\&D. Bandung: Alfabeta.

Tjiptono, Fandy. 2005. Pemasaran Jasa. Edisi pertama. Yogyakarta; Penerbit. Bayumedia Publishing

Tjiptono, Fandy. Service Management Mewujudkan Layanan Prima. 2012. Penebit ANDI : Yogyakarta.

Tu, Rungting. 2004. Beyond Service Quality And Expectation: The Critical Impact Of Emotions And Service Experience On
Customer Satisfaction. Disertasi. University of North Carolina. Chapel Hill. Zeithaml, Valarie A., Leonard L. Berry and A. Parasuraman (1988), "Communication and Control Processes in the Delivery of Service Quality," Journal of Marketing, 52 (April), 35-48.

Zeithaml, Valarie A., Leonard L. Berry and A. Parasuraman (1996), "The Behavioral Consequences of Service Quality," Journal of Marketing, 60 (April), 31-46 